\title{
Heterotropik Gebelik: 7 Haftalık Kornual Rüptüre Ektopik Gebelik ve 38. Gebelik Haftasına Ulaşan İntrauterin Gebelik: Olgu Sunumu
}

Heterotopic Pregnancy: 7th Week Cornual Ruptured Ectopic Pregnancy and

Intrauterine Pregnancy Reaching 38th Gestational Week

\author{
Ünal TÜRKAY ${ }^{1}$, Fulya DEMET ${ }^{1}$, Ayfer Özer CORA ${ }^{1}$ \\ Hasan TERZI ${ }^{1}$, Yasemin ÇOBANYILDIZI ${ }^{1}$
}

1. S.B.Ü. Kocaeli Derince Ĕ̆itim Araştırma Hastanesi Kadın Hastalıkları ve Doğum Kliniği, Kocaeli

\section{$\ddot{O Z Z E T}$}

Giriş: Intrauterin ve ekstrauterin gebeliğin birlikte olmasl olarak tanimlanan heterotopik gebelik spontan olarak oldukça nadir görülmesine rağmen yardımcı üreme teknikleri (YÜT). ile oluşan gebeliklerde 100 de 1 olarak görülmektedir.

Olgu: 26 yaşında gravida 1 Parite 0 olan hasta şiddetli karın ă̆rısı şikâyeti ile acil polikliniğimize başvurdu. Özgeçmişinde geçirilmiş batın operasyonu, endometriozis ve pelvik inflamatuvar hastallk tespit edilmedi. YÜT ile oluşan gebeliği olan hastanin yapılan transvajinal usg sinde 7 haftalik intrauterin canli gebelik ve yaygin serbest sivı tespit edildi. Akut batın tespit edilen hastaya acil laparatomi cerrahi uyguland. Operasyonda literatürdede oldukça nadir görülen kornual rüptüre ektopik gebelik (heterotopic gebelik). tanisı konuldu. Kornual onartm yapilan ve operasyon sonrast intrauterin gebeliğ 38. gebelik haftasina ulaşan ve nihayetinde sağliklı bir bebek doğuran bu olgumuzu sizlerle paylaşmayı amaçladık.

Sonuç: YÜT oluşan gebeliklerde heterotopik gebelik açısindan kapsamli transvaginal ultrasonografi yapılmall. Akut batın tablosu ile başvuran hastalarda maternal mortalite açısından cerrahi konusunda tereddüt edilmemelidir.

Anahtar Kelimeler: heterotopik gebelik, rüptüre rornual gebelik, intrauterin gebelik, laparatomy

\section{ABSTRACT}

Introduction: Heterotopic pregnancy, defined as the coexistence of intrauterine and extrauterine gestation, is rarely seen spontaneously, but is seen as 1 in 100 pregnancies with assisted reproductive techniques (ART)

Case: 26 years old gravida 1 Parity 0 patient applied to our emergency polyclinic with severe abdominal pain. Past history were not detected such as abdominal operation, endometriosis and pelvic inflammatory disease.

İletişim:

Sorumlu Yazar: Ünal TÜRKAY

Adres: S.B.Ü. Kocaeli Derince Eğitim Araştırma Hastanesi Kadın Hastalıkları ve Doğum Kliniği, Kocaeli, Türkiye

Tel: +90 (262) 3178000

E-Posta: unalturkay@yahoo.com

Makale Geliş: 23.06.2017

Makale Kabul: 08.09.2017

DOI: http://dx.doi.org/10.16948/zktipb.323548
In the transvaginal ultrasound of the pregnant patient with ART, 7 weeks of intrauterine live pregnancy and common free fluid were detected. Emergency laparotomy was applied to the patient who was diagnosed as acute abdomen. In operation, a rarely seen cornual ruptured ectopic pregnancy (heterotopic pregnancy). in the literature was diagnosed. We aimed to share with you our patient who has delivered a healthy baby after reaching the gestational week of 38th week of intrauterine pregnancy which has been treated with cornual repair.

Conclusion: Comprehensive transvaginal ultrasonography should be performed for heterotopic pregnancy in pregnancies with ART. Patients presenting with an acute abdomen should not be hesitated about surgery in terms of maternal mortality.

Keywords: heterotopic pregnancy, ruptured cornual pregnancy, intrauterine pregnancy, laparotomy

\section{GíRiş}

Heterotopik gebelik intrauterin ve ektrauterin gebeliğin birlikte olması olarak tanımlanır. İlk olarak 1708 de bir otopsi esnasinda Duvarney tarafindan tanımland1. 1948 yılında DeVoe ve Pratt heterotopik gebelik insidansin 30.000 gebelikte 1 olarak belirledi (1). Heterotopik gebelik, nadir bir durum olmasına rağmen, yardımcı üreme tekniklerinden (YÜT). sonra daha büyük bir oranda görülmektedir . Spontan durumda 30.000 hamilelikte yaklaşık 1 olan bu insidans $(2,3)$ YÜT sonras 1 1/100 olarak belirlenmiştir (4). Heterotopik gebelikler bilateral tubal gebelik, abdominal-intrauterin gebelik veya cornual-intrauterin gebelik olarak görülebilir (5). Kornual gebelik embriyonun fallop tüpünün intramural kısmında yerlereşmesi ile oluşur ve ektopik gebeliklerin \%2 sinde görülür (6). Kornual gebelik tanı ve tedavide gecikme olması durumunda yüksek maternal morbiditeye hatta mortaliteye sahip olan potansiyel olarak ölümcül bir durumdur. Bizde literatürde oldukça nadir görülen kornual rüptüre ektopik gebelik ve intrauterin canlı gebelik tespit edip opere ettiğimiz ve sonrasında intrauterin gebeliğin miyada ulaşıp sectio ile doğurtulduğu olguyu sunmayı amaçladık. 


\section{OLGU}

26 yaşında Gravide 1, Parite 0 olan bayan hasta Kocaeli Derince Eğitim Araștırma Hastanesi acil polikliniğine gebelik ve şiddetli karın ağrısı şikayeti ile başvurdu. Anamnezinde daha önce herhangi bir gebeliği , geçirilmiş bir batın operasyonu, endometriozis ve pelvik inflamatuar hastalığı (PID). öyküsü olmadığı bilgisi alınd. Erkek faktör nedeni ile 5 hafta önce YÜT ile iki embriyo transferi olduğunu ifade eden hastanın yapılan batın muayenesinde rebaund ve defans tespit edildi. Tansiyon arteriel: 70/50 mmHg, nabız:105 atım/dakika olarak ölçüldü.

Yapılan transvajinal ultrasonografide CRL: $10.4 \mathrm{~mm} 7$ hafta 1 gün ile uyumlu intrauterin tekil canlı gebelik ve batın içi yaygın serbest s1v1 tespit edildi. Yapılan tam kan sayımında Hemoglobin (hgb) 8,6 gr/dL olan ve akut batın tespit edilen hastaya acil laparatomi yapildi. Batın içi gözlemde sol cornual bölgeden yaklaşık $2 \mathrm{~cm}$ 'lik rüptüre ektopik gebelik ve batın içi yaklaşı $2000 \mathrm{ml}$ serbest kan tespit edildi (Resim 1).

Operasyonda hastaya sol kornual bölge kısmi rezeksiyon yapılıp primer sütüre edildi (Resim 2).

Operasyon esnasinda ve sonrasinda toplam 3 ünite eritrosit süspansiyonu ve 1 ünite taze donmuş plazma verildi. Postoperatif 3 (üç) gün takibinde problemi olmayan hasta poliklinik kontrolü önerilerek taburcu edildi.

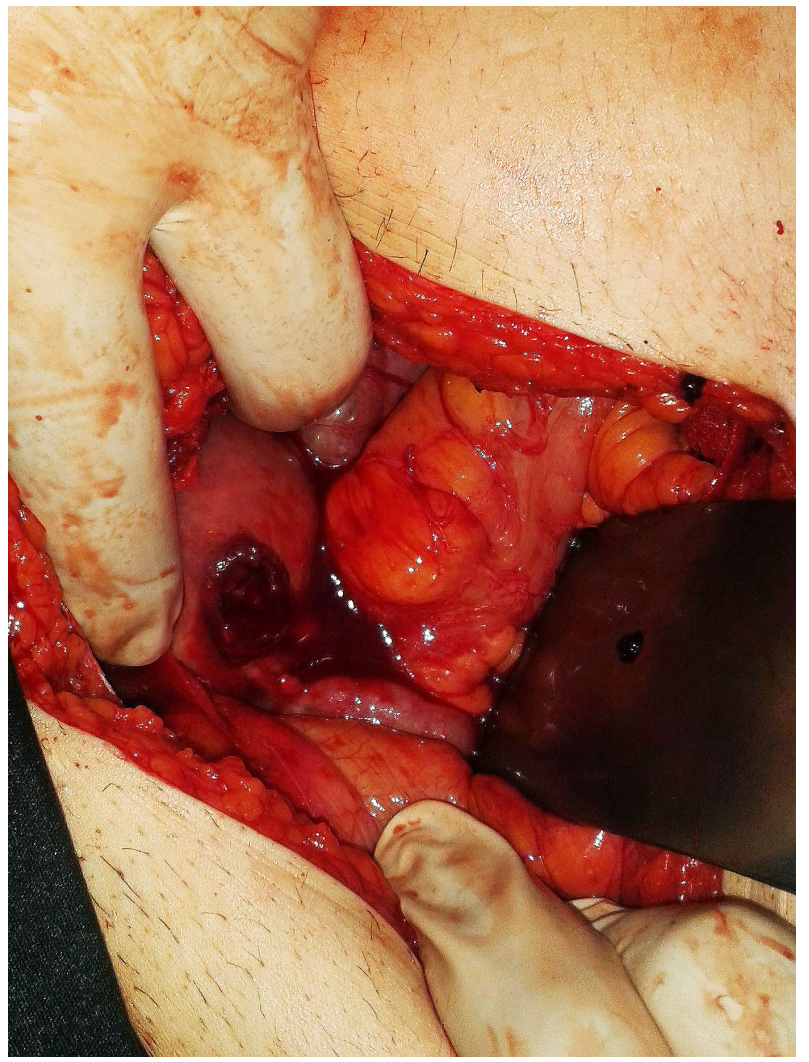

Takiplerinde problem olmayan hastanın 38. Gebelik haftasında diș merkezde sezeryan ile 3330 gr canlı erkek bebek doğurtulduğu ve Sezeryan operasyonu esnasinda ve postoperatif takibinde bir komplikasyon görülmediği bilgisi alındı.

\section{TARTIŞMA}

Ektopik gebelik, döllenmiş bir ovumun enndometrial kavite dişında bir alana implante olması sonucu birinci trimester maternal morbidite ve mortalitenin önde gelen nedenlerinden biri olmaya devam etmektedir $(7,8)$. Heterotopic gebeliğin spontan görülme insidans 30000 de 1 iken bu insidans YÜT sonrasında 100 de 1 e yükselmiştir (4). İyi bir özgeçmiş sorgulaması ile heterotopic gebeliğin risk faktörleri olan fertilite tedavisi ve tubal patolojiler (örneğin: PID, endometriozis veya önceden geçirilmiş tubal cerrahi) tanımlanabilir (9). Bizim olgumuzun özgeçmiş sorgulamasında YÜT ile 2 (iki) embriyo transeferi sonrası gelișen heterotopic gebelik tespit edilmiştir. Ektopik gebeliklerin \% 70 i 5 ile 8. Gebelik haftaları arasında , $\% 20$ i gebeliğin 9-10. Haftaları arasında, \%10 uda gebeliğin 10 haftasından sonra tanı alır (10) Erken sonografik muayene YÜT ile oluşan gebeliklerde yaygin olarak kullanılmaktadır. Ancak heterotopic kadınlarda intrauterin gebelikten dolayı ektopik gebelik geç fark edilebilir (11). Heterotopik ve ektopik gebeliğin tanısında yüksek çözünürlüklü transvajinal ultrason (tv-usg). önemli bir yardimcidır. Rutin tv-usg taraması YÜT kullanan hastalarda ektopik yada heterotopik gebelik için embriyo transferinden 4-6 hafta sonra önerilir.

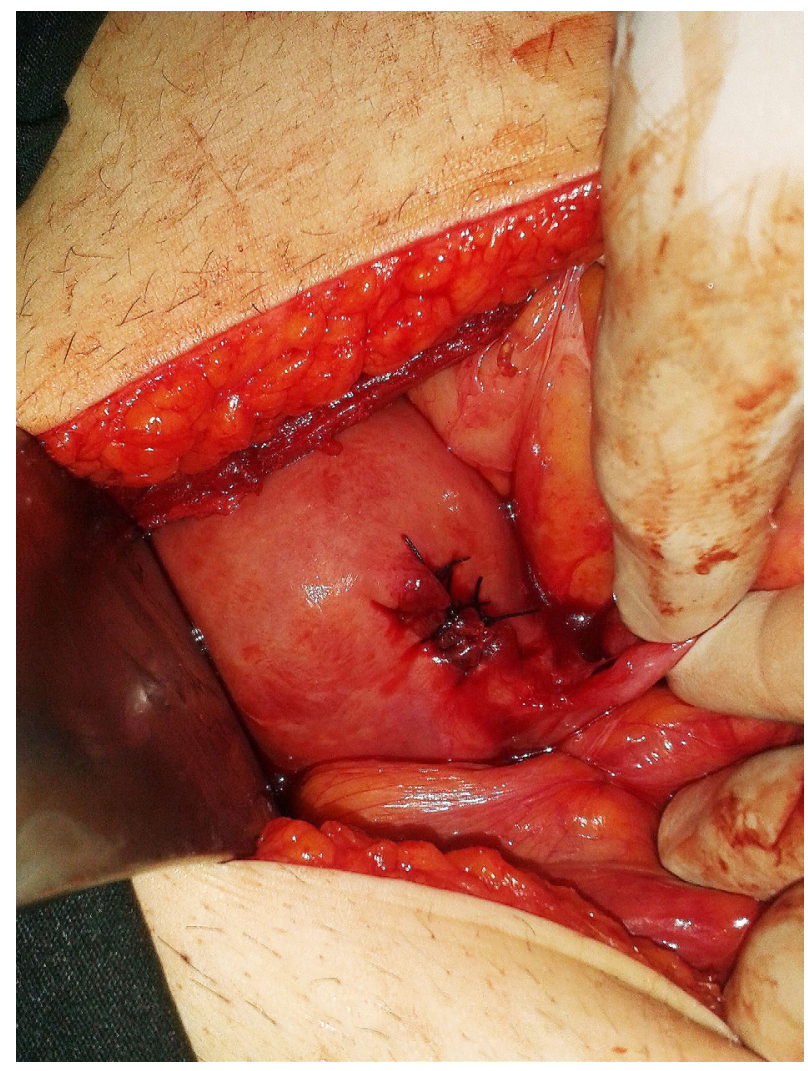


Olgumuz embriyo transferinden 5 hafta sonra akut batın ile acil polikliniğimize başvurmuștur. Ancak 1 hafta önceki kontrolünde heterotopik gebelik tespit edilememiş olup kliniğimize akut batın tablosu ile başvurmuștur.

Uterin corn uterin ve ovarian arterlerin dallarından dolayı oldukça iyi kanlanan bir bölgedir. Kornual gebelik ve inrauterin gebeliğin birlikteliği durumunda ve tanıda gecikme sonucunda kornual bölgeden gelişen rüptürlerde hayatı tehdid eden durumlar görülebilir (12). Habana ve arkadaşları, histerektomiye kadar gidilebilecek masif kanamalara yol açan kornual ektopik rüptür insidansını \% 48.6 olarak belirtmişlerdir (5). Bizim olgumuzda yapılan kontrolünde transvajinal ultrasonda intrauterin gebeliğe odaklanılmasindan dolayı gözden kaçan cornual gebelik rüptürü ile hayatı tehdit eden bir durumla karşımıza gelmiştir. Ancak hastanın acil şartlarda hızlı tanı almasi ve tedavi edilmesi nedeni ile maternal mortalite ve morbidite görülmemiştir.

Laparotomi gerektiren akut olgularda, sağlıklı intrauterin gebeliğin devamı için uterusa minimal travma ile operasyon tamamlanmalıdır. Heterotopik gebeliklerde ekstrauterin gebelik için laparotomi yapıldı ğında $\% 9$ oranında abort ya da ölü doğum, \%16 erken doğum ve \%75 zamanında doğum bildirilmiştir (13). Heterotopic gebelik nedeni ile opere edilen hastalarda devam eden ve sağlıklı infant doğurma oranını Yu ve arkadaşlan1 \%88 olarak tespit etmişlerdir (14). Operasyon sırasında özellikle corpus luteum içeren overin kan akımının korunmasına özen gösterilmesi üzerinde durulmuştur (15).

Olgumuzda operasyon esnasinda intrauterin gebelikten dolay1 uterus travmatize edilmemiş olup intrauterin gebeliğin miyada kadar ulaştığ 1 izlenmektedir.

Sonuç olarak YÜT ile birlikte heterotropik gebelik oranı artmıştır. Mortalitesi yüksek bir durum ile karşılaşmamak için heterotopik gebelik açısından ultrasonografi ile kapsamlı adneksiyel tarama yapılmalıdır. Heterotopik gebelik şüphesi olan ve durumu stabil olmayan gebelerde hayat kurtarıcı bir işlem olan cerrahi girişim bir an önce uygulanmalıdır. Opreasyon esnasında intrauterin gebeliği için uterusa mümkün olduğunca az travma uygulanmalıdır.

\section{KAYNAKLAR}

1. Brunette DD, Roline C. Heterotopic pregnancy resulting from in vitro fertilization. Am J Emerg Med 2011;29:960.

2. Ebner T, Yaman C, Moser M, Sommergruber M, Polz W, Tews $G$. Embryo fragmentation in vitro and its impact on treatment and pregnancy outcome. Fertil Steril. 2001;76:281-5. (PubMed)

3. Pan HS, Chuang J, Chiu SF, Hsieh BC, Lin YH, Tsai YL, et al. Heterotopic triplet pregnancy: Report of a case with bilateral tubal pregnancy and an intrauterine pregnancy. Hum Reprod. 2002;17:1363-6. (PubMed)

4. Maruotti GM, Sarno L, Morlando M, Sirico A, Martinelli P, Russo T. Heterotopic pregnancy: it is really a rare event? The importance to exclude it not only after in vitro fertilization but also in case of spontaneous conception.Fertil Steril. 2010;94:e49.

5. Habana A, Dokras A, Giraldo JL, Jones EE. Cornual heterotopic pregnancy: contemporary management options. Am J Obstet Gynecol 2000;182:1264-70.

6. Surbone A, Cottier O, Vial Y, Francini K, Hohlfeld P, Achtari C. Interstitial pregnancies' diagnosis and management of interstitial pregnancy - a series of eleven cases. Swiss Med Wkly 2013;143:w13736.

7. Refaat B, Dalton E, Ledger WL. Ectopic pregnancy secondary to in vitro fertilisation-embryo transfer: pathogenic mechanisms and management strategies. Reprod Biol Endocrinol $2015 ; 13: 30$.

8. Khan KS, Wojdyla D, Say L, et al. WHO analysis of causes of maternal death: a systematic review. Lancet 2006;367:1066-74.

9. Kwok TC, Morgan G. Think heterotopic: a case report of heterotopic pregnancy detected on thorough ultrasonography. J Med Cases 2012;3:326-8.

10. Shah Y, Zevallos H, Moody L. Combined intra and extrauterine pregnancy: a diagnostic challenge. J Reprod Med. 1980;25:290e292.

11. Soriano D, Vicus D, Schonman R, et al. Long-term outcome after laparoscopic treatment of heterotopic pregnancy: 19 cases. JMin Invas Gynecol. 2010;17:321e324.

12. Lam PM, Lok IH, Yip SK. Two cases of heterotopic cornual pregnancy with initially missed diagnosis. Aust NZJ Obstet Gynaecol 2004;44:256-9.

13. Reece ED, Petrie RH, Sirmons MF, Finster M, Todd WD. Combined intrauterine and extrauterine gestation: a review. Am J Obstet Gynecol, 1983;146:323-330.

14. Y. Yu, W. Xu, Z. Xie, Q. Huang, S. Li. Management and outcome of 25 heterotopic pregnancies in Zhejiang, China. European Journal of Obstetrics \& Gynecology and Reproductive Biology 2014; 180: 157-161

15.Glassner MJ, Aron E, Eskin BA. Ovulation induction with clomiphene and rise in heterotopic pregnancies: a report of two cases. J Reprod Med, 1990;35:175-178. 